\title{
Can the Obesity Surgery Mortality Risk Score predict postoperative complications other than mortality?
}

\author{
Piotr Major ${ }^{1}$, Michał Wysocki ${ }^{2}$, Michał Pędziwiatr ${ }^{1}$, Piotr Małczak ${ }^{1}$, Magdalena Pisarska ${ }^{1}$, Marcin Migaczewski ${ }^{1}$, \\ Marek Winiarski ${ }^{1}$, Andrzej Budzyński ${ }^{1}$ \\ ${ }^{1} 2^{\text {nd }}$ Department of Surgery, Jagiellonian University, Medical College, Krakow, Poland \\ ${ }^{2}$ Students' Scientific Group at $2^{\text {nd }}$ Department of Surgery, Jagiellonian University, Medical College, Krakow, Poland
}

Videosurgery Miniinv 2016; 11 (4): 247-252

DOI: https://doi.org/10.5114/wiitm.2016.64448

\begin{abstract}
Introduction: Laparoscopic sleeve gastrectomy (LSG) and laparoscopic Roux-en-Y gastric bypass (LRYGB) are bariatric procedures with acceptable risk of postoperative morbidities and mortalities, but identification of high-risk patients is an ongoing issue. DeMaria et al. introduced the Obesity Surgery Mortality Risk Score (OS-MRS), which was designed for mortality risk assessment but not perioperative morbidity risk.

Aim: To assess the possibility to use the OS-MRS to predict the risk of perioperative complications related to LSG and $L R Y G B$.

Material and methods: Retrospective analysis of patients operated on for morbid obesity was performed. Patients were evaluated before and after surgery. We included 408 patients (233 LSG, 175 LRYGB). Perioperative complications were defined as adverse effects in the 30-day period. The Clavien-Dindo scale was used for description of complications. Patients were assigned to five grades and three classes according to the OS-MRS results, then risk of morbidity was analyzed.

Results: Complications were observed in $30(7.35 \%)$ patients. Similar morbidity was related to both procedures $(O R=1.14,95 \% \mathrm{Cl}: 0.53-2.44, p=0.744)$. The reoperation and mortality rates were $1.23 \%$ and $0.49 \%$ respectively. There were no significant differences in median OS-MRS value between the group without and the group with perioperative complications. There were no significant differences in OS-MRS between groups $(p=0.091)$. Obesity Surgery Mortality Risk Score was not related to Clavien-Dindo grades $(p=0.800)$.

Conclusions: It appears that OS-MRS is not useful in predicting risk of perioperative morbidity after bariatric procedures.
\end{abstract}

Key words: complications, bariatric surgery, Obesity Surgery Mortality Risk Score.

\section{Introduction}

Laparoscopic sleeve gastrectomy (LSG) and laparoscopic Roux-en-Y gastric bypass (LRYGB) are associated with acceptable risk of postoperative morbidity and mortality [1-7]. However, identification of high-risk patients plays an important role in everyday work of the bariatric team $[8,9]$. It may help in the process of selection of the most appropriate procedure for those patients, preoperative optimization of therapy for co-morbidity, and enhanced vigilance in the perioperative period [9-12].

DeMaria et al. introduced the Obesity Surgery Mortality Risk Score (OS-MRS) [13], which was validated in a US multi-center study [14] and in a Canadian study [15]. The OS-MRS uses five clinical

\section{Address for correspondence}

Piotr Major MD, PhD, $2^{\text {nd }}$ Department of Surgery, Jagiellonian University, Medical College, 21 Kopernika St, 31-501 Krakow, Poland,

phone: +48 693313 948, e-mail: majorpiotr@gmail.com 
risk factors for assignment to one of three distinct classes. The OS-MRS has been applied previously for mortality risk assessment, but not risk of perioperative morbidity.

Since mortality from laparoscopic bariatric surgery is a rare event, we tried to apply OS-MRS in assessment of perioperative bariatric procedures' morbidity.

\section{Aim}

We aimed to assess the use of the OS-MRS to predict the risk of perioperative complications related to LSG and LRYGB.

\section{Material and methods}

\section{Material}

From April 2009 to October 2015, 415 patients were operated on for morbid obesity in the $2^{\text {nd }}$ Department of General Surgery of Jagiellonian University Medical College. In the study we included 408 patients ( 256 women, 152 men, 42.5 years old on average). In 233 patients LSG was performed (159 women, 74 men, mean age: $40.34 \pm 10.83$ ) and in 175 LRYGB (97 women, 78 men, mean age 45.95 \pm 10.06 ) (Figure 1). Patients' clinical characteristics, including surgical data, are presented in Table I. The association between OS-MRS class and incidence of the study endpoint in laparoscopic bariatric surgery is presented in Table II.

\section{Methods}

The study was based on retrospective analysis of prospectively collected data of patients operated on for morbid obesity. Inclusion criteria for bariatric operations were Guidelines of the Metabolic and Bariatric Section of the Polish Surgical Society, i.e. body mass index (BMI) $\geq 35 \mathrm{~kg} / \mathrm{m}^{2}$ with obesity comorbidities or BMI $\geq 40 \mathrm{~kg} / \mathrm{m}^{2}$ with or without comorbidities. Patients were evaluated prior to surgery and afterwards underwent LSG or LRYGB. Patients' demographic and clinical data, including a detailed description of the intraoperative adverse effects and perioperative complications, were obtained. Perioperative complications were defined as adverse effects which occurred in the 30 days after the procedure. The Clavien-Dindo scale was used for description of complications [16].

The risk of postoperative complications was assessed using the OS-MRS scale. One point was assigned to each of 5 preoperative variables including $\mathrm{BMI} \geq 50 \mathrm{~kg} / \mathrm{m}^{2}$, male gender, arterial hypertension, known risk factors for pulmonary embolism, e.g. previous thromboembolism, preoperative vena cava filter, hypoventilation, pulmonary hypertension and age $\geq 45$ years. Patients were divided into five categories according to the OS-MRS results. The class of the risk assigned to each patient was dependent on the total points obtained. A score of zero or one point $=$ class $A$; two or three points = class B; and four or five points $=$ class $C$.

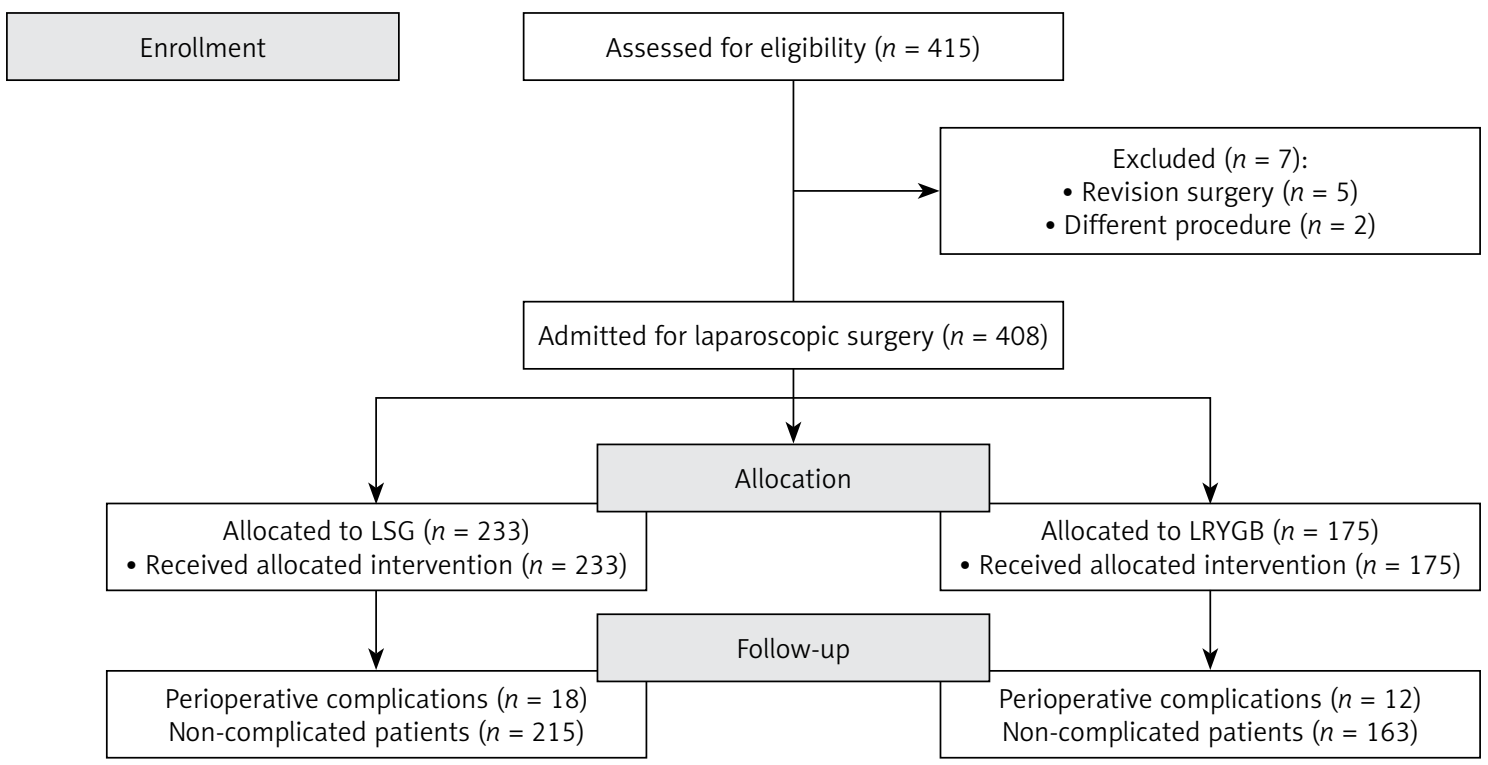

Figure 1. Study flow chart 
Table I. Patients' characteristics

\begin{tabular}{|c|c|c|c|}
\hline Parameter & LSG & LRYGB & $P$-value \\
\hline \multicolumn{4}{|l|}{ Factors dependent on patient: } \\
\hline Number of patients, $n(\%)$ & $233(57.11)$ & $175(42.89)$ & - \\
\hline Females, $n(\%)$ & $159(38.97)$ & $97(23.77)$ & \multirow[t]{2}{*}{0.008} \\
\hline Males, $n(\%)$ & $74(18.14)$ & $78(19.12)$ & \\
\hline Age, mean \pm SD [years] & $40.34 \pm 10.83$ & $45.95 \pm 10.06$ & 0.302 \\
\hline Maximal preoperative weight, median (IQR) $[\mathrm{kg}]$ & $132(120 ; 147)$ & $141(126 ; 160)$ & $<0.001$ \\
\hline Maximal preoperative BMI, median (IQR) $\left[\mathrm{kg} / \mathrm{m}^{2}\right]$ & $45.91(42.48 ; 50.19)$ & $48.83(44.08 ; 54.08)$ & $<0.001$ \\
\hline Weight on day of surgery, median (IQR) [kg] & $130(117 ; 143)$ & $135(120 ; 155)$ & 0.004 \\
\hline BMI on day of operation, median (IQR) $\left[\mathrm{kg} / \mathrm{m}^{2}\right]$ & $44.82(41.33 ; 48.55)$ & $46.76(41.87 ; 52.63)$ & 0.002 \\
\hline Preoperative weight loss, median (IQR) $[\mathrm{kg}]$ & $2(0 ; 6)$ & $4(0 ; 9)$ & 0.002 \\
\hline \multicolumn{4}{|l|}{ Factors dependent on procedure: } \\
\hline Operative time, median (IQR) [min] & $110(85 ; 140)$ & $140(100 ; 180)$ & $<0.001$ \\
\hline Additional procedure during procedure, $n(\%)$ & $3(1.29)$ & $4(2.29)$ & 0.702 \\
\hline Intraoperative adverse effects, $n(\%)$ & $4(1.72)$ & $10(5.71)$ & 0.055 \\
\hline Operated on by experienced operator, $n(\%)$ & $28(12.02)$ & $104(59.43)$ & \multirow[t]{2}{*}{$<0.001$} \\
\hline Operated on by operator on bariatric learning curve, $n(\%)$ & $205(87.98)$ & $71(40.57)$ & \\
\hline
\end{tabular}

Table II. Association between OS-MRS class and incidence of the study endpoint in laparoscopic bariatric surgery (total $N=408)$

\begin{tabular}{|lccc|}
\hline OS-MRS class & OS-MRS Grade & Number of patients, $n(\%)$ & Endpoint $^{\mathrm{b}}, n$ (\% of patients) \\
\hline A & $0-1$ & $199(48.77)$ & $20(4.9)$ \\
\hline B & $2-3$ & $115(28.19)$ & $4(0.98)$ \\
\hline C & $4-5$ & $94(23.04)$ & $6(1.47)$ \\
\hline
\end{tabular}

a Number of risk factors: age $\geq 45$ years, male gender, $B M I \geq 50 \mathrm{~kg} / \mathrm{m}^{2}$, hypertension (or treatment for hypertension) and high-risk status for thromboembolism. ${ }^{b}$ End point: perioperative morbidity, including mortality, defined as laparoscopic bariatric surgery adverse effects diagnosed in the 30-day perioperative period.

\section{Ethics}

All procedures performed in studies involving human participants were in accordance with the ethical standards of the institutional and national research committee and with the 1964 Declaration of Helsinki and its later amendments or comparable ethical standards. The study was approved by the Bioethics Committee of the Jagiellonian University.

\section{Statistical analysis}

To assess the significance of the observed intergroup differences of frequencies of qualitative data, the $\chi^{2}$ test with and without Yates' correction and Fisher's exact test were used. The quantitative data were processed with Student's t-test or the Mann-Whitney test for non-parametric variables.
Univariate logistic regression analyses were conducted for OR with $95 \% \mathrm{Cl}$ calculations. Statistical significance was observed with $p$-value under 0.05 . Statistica 10.0 PL software was used for the conducted analysis.

\section{Results}

Complications were observed in 30 (7.35\%) patients. Similar morbidity was related to both procedures (LRYGB vs. LSG; OR = 1.14, 95\% Cl: 0.53-2.44, $p=0.744)$. The most common complication was rhabdomyolysis, observed in 9 patients (2.2\% of total). The 30-day reoperation rate and mortality rate were $1.23 \%$ and $0.49 \%$ respectively. Causes of death were pulmonary embolism and rhabdomyolysis in the first (OS-MRS class C), and operation site's strangulated hernia with peritonitis and jejunojejunal anastomo- 
sis leak in the second patient (OS-MRS class B). Both patients were submitted to LRYGB (Table III).

The OS-MRS yields quantitative, but it could be converted to qualitative categories. The Mann-Whitney test revealed no statistically significant difference between the median OS-MRS value of $3(2-3)$ of the group without perioperative complications and the median OS-MRS value of 3 (1-3) calculated for the group with perioperative complications.

The study revealed no statistically significant difference in OS-MRS class between the group with complications and the group without complications $(p=0.091)$. We did not observe a significant dif- ference between groups A and B in OS-MRS class $(p=0.059)$, or between $A$ and $C(p=0.513)$ or $B$ and $C$ $(p=0.303)$ or $\mathrm{A}$ and $\mathrm{B}+\mathrm{C}(p=0.095)$ (Table IV).

We did not observe any statistically significant difference in OS-MRS between different Clavien-Dindo grades $(p=0.8)$. There was no significant relation between frequency of A or B + C OB-MRS class categories and Clavien-Dindo class I-II or III-V categories $(p=0.648)$ (Table V).

Finally, we used univariate logistic regression to assess the influence of increasing OS-MRS class or grade on the odds ratio of morbidity. The odds ratio of perioperative complications did not increase

Table III. Perioperative ( $\leq 30$ days) complications according to Clavien-Dindo scale

\begin{tabular}{|c|c|c|c|c|}
\hline C-D Grade & Complications & $N(\%)$ & LSG & LRYGB \\
\hline \multirow[t]{2}{*}{5} & $\begin{array}{l}\text { Pulmonary embolism and rhabdomyolysis } \\
\text { (patient death) }\end{array}$ & $1(0.25)$ & 0 & $1(0.57 \%)$ \\
\hline & $\begin{array}{c}\text { Peritonitis, strangulated operation site hernia, } \\
\text { jejunojejunal anastomosis leak (relaparotomy, } \\
\text { patient death) }\end{array}$ & $1(0.25)$ & 0 & $1(0.57 \%)$ \\
\hline $4 b$ & Cardiorespiratory failure (ICU stay) & $2(0.49)$ & $1(0.43 \%)$ & $1(0.57 \%)$ \\
\hline $4 a$ & Pneumonia, ARDS (ICU stay) & $1(0.25)$ & 0 & $1(0.57 \%)$ \\
\hline \multirow[t]{3}{*}{$3 b$} & Gastrointestinal leakage & $6(1.53)$ & $5(2.15 \%)$ & $1(0.57 \%)$ \\
\hline & $\begin{array}{l}\text { Bleeding from suture line } \\
\text { (relaparoscopy) }\end{array}$ & $2(0.49)$ & $1(0.43 \%)$ & $1(0.57 \%)$ \\
\hline & $\begin{array}{l}\text { Petersen's space hernia } \\
\text { (relaparoscopy) }\end{array}$ & $1(0.25)$ & 0 & $1(0.57 \%)$ \\
\hline \multirow[t]{2}{*}{2} & Pneumonia & $1(0.25)$ & 0 & $1(0.57 \%)$ \\
\hline & Fever of unknown origin & $1(0.25)$ & 0 & $1(0.57 \%)$ \\
\hline \multirow[t]{5}{*}{1} & Delayed gastric emptying* & $5(1.23)$ & $4(1.72 \%)$ & $1(0.57 \%)$ \\
\hline & Dehydration* & $1(0.25)$ & $1(0.43 \%)$ & 0 \\
\hline & Prolonged drainage & $1(0.25)$ & $1(0.43 \%)$ & 0 \\
\hline & Rhabdomyolysis & $8(1.96)$ & $6(2.58 \%)$ & $2(1.14 \%)$ \\
\hline & Total & $30(7.35)$ & $18(7.73 \%)$ & $12(6.86 \%)$ \\
\hline
\end{tabular}

${ }^{*} 1$ patient was diagnosed with both complications.

Table IV. Pearson's $\chi^{2}$ test of intergroup differences in OS-MRS frequencies

\begin{tabular}{|c|c|c|c|c|c|c|}
\hline \multirow[t]{2}{*}{ OS-MRS class } & \multirow{2}{*}{$\begin{array}{l}\text { Group with } \\
\text { complications }\end{array}$} & \multirow{2}{*}{$\begin{array}{l}\text { Group without } \\
\text { complications }\end{array}$} & \multicolumn{4}{|c|}{$P$-value } \\
\hline & & & A vs. B & B vs. C & A vs. C & $A$ vs. $B+C$ \\
\hline A & $4(13.33 \%)$ & 111 (29.37\%) & 0.059 & 0.303 & 0.513 & 0.095 \\
\hline B & 20 (66.67\%) & 179 (47.35\%) & & & & \\
\hline C & $6(20.00 \%)$ & 88 (23.28\%) & & & & \\
\hline
\end{tabular}


Table V. OS-MRS classes categorized according to Clavien-Dindo grades

\begin{tabular}{|lccccccc|}
\hline \multirow{2}{*}{ OS-MRS class } & \multicolumn{5}{c}{ Clavien-Dindo grade } & P-value \\
\cline { 3 - 6 } & & I & II & III & IV & V \\
\hline A & $n$ (\% of total) & $2(6.67)$ & $0(0.00)$ & $1(3.33)$ & $1(3.33)$ & $0(0.00)$ & 0.800 \\
\hline B & $n$ (\% of total) & $9(30.00)$ & $1(3.33)$ & $7(23.33)$ & $2(6.67)$ & $1(3.33)$ \\
\hline C & $n$ (\% of total) & $3(10.00)$ & $1(3.33)$ & $1(3.33)$ & $0(0.00)$ & $1(3.33)$ \\
\hline
\end{tabular}

significantly with either OS-MRS grade (OR = 1.24, 95\% Cl: $0.94-1.63, p=0.133)$ or with OS-MRS class $(\mathrm{OR}=0.78,95 \% \mathrm{Cl}: 0.46-1.32, p=0.352)$.

Regarding mortality, OS-MRS did not predict an increase in the odds ratio of patients' death (OSMRS grade: $\mathrm{OR}=1.95,95 \% \mathrm{Cl}: 0.58-6.60, p=0.281$; OS-MRS class: $\mathrm{OR}=0.31,95 \% \mathrm{Cl}: 0.03-3.12, p=$ 0.316).

\section{Discussion}

One of the first attempts to create a simple tool for preoperative assessment of a morbidly obese patient's mortality risk was the OS-MRS, proposed in 2007 by DeMaria et al. [13], which was validated by the author [14] and in other studies [15, 17]. Sarela et al. tried to use it for prediction of perioperative morbidity [18]. Orłowski et al. reported that the OS-MRS can be a useful clinical tool in the decision about an optimal bariatric procedure, depending on the risk of postoperative complications [19]. Other scoring systems were developed by Flum et al. based on analyzing the results of the Longitudinal Assessment of Bariatric Surgery (LABS) [20], or metabolic acuity score by Blackstone et al. [21] or scales of Gupta et al. and Turner et al. derived from the National Surgical Quality Improvement Program (NSQIP) database of the American College of Surgeons [22, 23].

The simplicity of the OS-MRS scale encourages its use in common surgical practice, while using five clinical variables to estimate patients' postoperative risk preoperatively. A limitation is that this scale was developed for the analysis of mortality after LRYGB, although it was tested in predicting morbidity [18].

In this study we found limited value of OS-MRS for estimating the perioperative morbidity risk of morbidly obese patients submitted to laparoscopic bariatric procedures, including laparoscopic sleeve gastrectomy and laparoscopic Roux-en-Y gastric bypass. In our study there were no significant differences in OS-MRS grade between groups with and without perioperative complications. The OS-MRS classes did not significantly differ between groups.

Only a few studies have evaluated use of the OS-MRS in predicting postoperative morbidity risk. Sarela et al. demonstrated that the OS-MRS is independently predictive of the risk of postoperative adverse events after gastric band, Roux-en-Y gastric bypass, sleeve gastrectomy, or biliopancreatic diversion [18]. An increase in OS-MRS class resulted in an increase of postoperative adverse effects by $300 \%$. Similar results were recently presented in an analysis performed by Lorente et al. [24]. They demonstrated a significant association between the OS-MRS scale and morbidity increasing from $7.3 \%$ in group $A$ to $50 \%$ in group C. Our group included a similar number of patients, but univariate logistic regression did not demonstrate an influence of OS-MRS class or grade on increase in morbidity or mortality.

The use of the OS-MRS in prediction of mortality was recently confirmed in a systematic review by Thomas et al. [17]. Likew in our study, patients who died in the perioperative period were in higher OSMRS classes. Despite encouraging advantages, the OS-MRS failed to identify patients at higher postoperative morbidity risk and should be used according to its primary purpose.

\section{Conclusions}

The OS-MRS is not a useful tool in predicting risk of perioperative morbidity after bariatric procedures.

\section{Acknowledgments}

The publication of this article was supported by Faculty of Medicine, Jagiellonian University Medical College, Leading National Research Centre (KNOW) 2012-2017.

\section{Conflict of interest}

The authors declare no conflict of interest. 


\section{References}

1. Rosenthal Rj; International Sleeve Gastrectomy Expert Panel, Diaz AA, Arvidsson D, et al. International Sleeve Gastrectomy Expert Panel Consensus Statement: best practice guidelines based on experience of $>12,000$ cases. Surg Obes Relat Dis 2012; 8: 8-19.

2. Sauerland S., Angrisani L, Belachew M, et al. Obesity surgery: evidence-based guidelines of the European Association for Endoscopic Surgery (EAES). Surg Endosc 2005; 19: 200-21.

3. Nguyen NT, Wilson SE. Complications of antiobesity surgery. Nat Clin Pract Gastroenterol Hepatol 2007; 4: 138-47.

4. Maggard MA, Shugarman LR, Suttorp M, et al. Meta-analysis: surgical treatment of obesity. Ann Intern Med 2005; 142: 547-59.

5. Trastulli S, Desiderio J, Guarino S, et al. Laparoscopic sleeve gas trectomy compared with other bariatric surgical procedures: a systematic review of randomized trials. Surg Obes Relat Dis 2013; 9: 816-29.

6. Sanni A, Perez S, Medbery R, et al. Postoperative complications in bariatric surgery using age and BMI stratification: a study using ACS-NSQIP data. Surg Endosc 2014; 28: 3302-9.

7. Zellmer JD, Mathiason MA, Kallies KJ, Kothari SN. Is laparoscopic sleeve gastrectomy a lower risk bariatric procedure compared with laparoscopic Roux-en-Y gastric bypass? A meta-analysis. Am J Surg 2014; 208: 903-10.

8. Szewczyk T, Janczak P, Janiak A, et al. Laparoscopic sleeve gastrectomy -7 years of own experience. Videosurgery Miniinv 2014; 9: 427-35.

9. Szydłowski K, Frask A, Michalik M, et al. Complications after surgical treatment of obesity based on own material. Videosurgery Miniinv 2008; 3: 45-52.

10. Ghaferi AA, Birkmeyer JD, Dimick JB. Variation in hospital mortality associated with inpatient surgery. N Engl J Med 2009; 361: 1368-75.

11. Kaska L, Proczko M, Stefaniak T, et al. Redesigning the process of laparoscopic sleeve gastrectomy based on risk analysis resulted in 100 consecutive procedures without complications. Videosurgery Miniinv 2013; 8: 289-300.

12. Stanowski E, Paśnik K. Bariatric surgery - the current state of knowledge. Videosurgery Miniinv 2008; 3: 71-86.

13. DeMaria EJ, Portenier D, Wolfe L. Obesity surgery mortality risk score: proposal for a clinically useful score to predict mortality risk in patients undergoing gastric bypass. Surg Obes Relat Dis 2007; 3: 134-40.

14. DeMaria EJ, Murr M, Byrne TK, et al. Validation of the obesity surgery mortality risk score in a multicenter study proves it stratifies mortality risk in patients undergoing gastric bypass for morbid obesity. Ann Surg 2007; 246: 578-82.

15. Efthimiou E, Court O, Sampalis J, Christou N. Validation of Obesity Surgery Mortality Risk Score in patients undergoing gastric bypass in a Canadian center. Surg Obes Relat Dis 2009; 5 : 643-7.

16. Dindo D, Demartines N, Clavien PA. Classification of surgical complications: a new proposal with evaluation in a cohort of 6336 patients and results of a survey. Ann Surg 2004; 240: 205-13.
17. Thomas H, Agrawal S. Systematic review of obesity surgery mortality risk score: preoperative risk stratification in bariatric surgery. Obes Surg 2012; 22: 1135-40.

18. Sarela Al, Dexter SP, McMahon MJ. Use of the obesity surgery mortality risk score to predict complications of laparoscopic bariatric surgery. Obes Surg 2011; 21: 1698-703.

19. Orłowski M, Janik MR, Paśnik K, Jędrzejewski E. Usefulness of the Obesity Surgery Mortality Risk Score (OR-MRS) in choosing the laparoscopic bariatric procedure. Videosurgery Miniinv 2015; 10: 233-6.

20. Flum DR, Belle SH, King WC, et al.; Longitudinal Assessment of Bariatric Surgery (LABS) Consortium. Perioperative safety in the longitudinal assessment of bariatric surgery. N Engl I Med 2009; 361: 445-54.

21. Blackstone RP, MC Cortés. Metabolic acuity score: effect on major complications after bariatric surgery. Surg Obes Relat Dis 2010; 6: 267-73.

22. Turner PL, Saager L, Dalton J, et al. A nomogram for predicting surgical complications in bariatric surgery patients. Obes Surg 2011; 21: 655-62.

23. Gupta PK, Franck C, Miller WJ, et al. Development and validation of a bariatric surgery morbidity risk calculator using the prospective, multicenter NSQIP dataset. J Am Coll Surg 2011; 212: 301-9.

24. Lorente L, Ramón JM, Vidal P, et al. Obesity surgery mortality risk score for the prediction of complications after laparoscopic bariatric surgery. Cir Esp 2014; 92: 316-23.

Received: 22.08.2016, accepted: 26.10.2016. 